\title{
Marie-Magdaleine Chirol, L'Imaginaire de la ruine dans «A la recherche du temps perdu» de Marcel Proust
}

\section{Emanuele Kanceff}

\section{(2) OpenEdition}

12 Journals

\section{Edizione digitale}

URL: http://journals.openedition.org/studifrancesi/36602

DOI: $10.4000 /$ studifrancesi.36602

ISSN: 2421-5856

\section{Editore}

Rosenberg \& Sellier

\section{Edizione cartacea}

Data di pubblicazione: 1 juillet 2005

Paginazione: 194-195

ISSN: 0039-2944

\section{Notizia bibliografica digitale}

Emanuele Kanceff, «Marie-Magdaleine Chirol, L'Imaginaire de la ruine dans «A la recherche du temps perdu» de Marcel Proust», Studi Francesi [Online], 145 (XLIX | I) | 2005, online dal 30 novembre 2015 consultato il 19 avril 2021. URL: http://journals.openedition.org/studifrancesi/36602 ; DOI: https:// doi.org/10.4000/studifrancesi.36602

Questo documento è stato generato automaticamente il 19 avril 2021.

\section{(c)}

Studi Francesi è distribuita con Licenza Creative Commons Attribuzione - Non commerciale - Non opere derivate 4.0 Internazionale. 


\title{
Marie-Magdaleine Chirol, L'Imaginaire de la ruine dans «A la recherche du temps perdu» de Marcel Proust
}

\author{
Emanuele Kanceff
}

\section{NOTIZIA}

MARIE-MAGDALEINE CHIROL, L'Imaginaire de la ruine dans «A la recherche du temps perdu» de Marcel Proust, Birmingham, Alabama, Summa Publications, 2001, pp. 139.

1 La rovina giustifica e materializza il «tempo perduto». Il narratore della Recherche è stimolato dall'esperienza dolorosa del passato perduto a divenire l'architetto di una memoria che sfugge. Sono gli odori e i sapori che danno inizio al movimento di ricostruzione del ricordo, che si edifica «sulla rovina di tutto il resto». La presenza della rovina è dunque fondamentale sia come materia sia come giustificazione del tempo perduto. La rovina è, per affermazione del narratore stesso, inerente all'opera, il postulato necessario perché possa iniziare il lavoro di ricostruzione: solo a partire dalle rovine si può ricostruire all'indietro ciò che è stato travolto dalla distruzione del tempo. Su questi presupposti s'innesta la riflessione dell'autrice, che si domanda che cosa il tempo abbia veramente distrutto, o non ancora distrutto, se la rovina non sia un'altra forma d'arte, o un prodotto dell'immaginario, se non debba evocare che imperi o civiltà sepolte, com'è nella concezione comune, oppure possa prendere altre forme più vicine al sentire degli uomini, relative dunque alla sfera dei sentimenti. Inoltre, la rovina è necessariamente il prodotto del tempo, oppure può essere anche il prodotto istantaneo che appartiene al nostro tempo?

2 Prima di ogni altra, l'autrice definisce la "rovina anticipata" che il narratore della Recherche vede con lo sguardo di Hubert Robert, rovina presentita, prefigurata, spesso 
individuata da un chiaro di luna notturno, sia che si tratti del paesaggio di Combray o di quello di Parigi, sia che si tratti di prendere a modello celebri dipinti oppure il gusto dei proprietari di ville e giardini del comune di Combray, in cui la rovina anticipata diviene immortale come la sola casa che sia in grado di resistere al tempo. Ma naturalmente le città sono anche preda di una rovina storica, Parigi come Pompei, come Sodoma, in una dimensione parallela che è storica classica e biblica: e qui l'autrice instaura un parallelismo tra l'antica Baalbek e la Balbec della Recherche.

3 La rovina è anche un tema pittorico importante, tra Corot, Hubert Robert e Turner, la cui opera l'autrice esamina in relazione ai riferimenti nel romanzo proustiano. Ma l'iniziazione al tema della rovina non è per lo scrittore solo pittorica e l'autrice esamina il passaggio dalle rovine feudali osservate nelle passeggiate giovanili dello scrittore e la rovina immaginaria che esse hanno contribuito a costruire: realtà, quest'ultima, di valenza poetica e simbolica, dai contorni sensuali, elemento di una passione distruttrice, che il narratore scoprirà lentamente e maturerà con il tempo.

4 La seconda parte del volume è dedicata ad un'analisi puntuale dei Jet d'eau di Hubert Robert, che diviene metafora del ricordo e dell'oblio. Segue la parte della studio dedicata al Temps retrouvé: dal paesaggio umano in rovina, sia esso corpo sociale o individuale, alla rovina istantanea nella petrificazione dei personaggi e del tempo, alla rovina come vanità e danza macabra, sia essa trasformazione della realtà che personificazione del macabro.

Ma, dalla consapevolezza della vecchiaia, dalla spettacolo devastato del mondo, dalla fortezza metaforica assediata da ogni parte dal tempo, nasce la pietra angolare della scrittura, elemento salvifico che trasforma la tragedia in occasione d'ispirazione: sicché la rovina è il fondamento dell'opera, "une colonne oubliée de temps vivant vécu par moi". 